BEST EVIDENCE EQUIPMENT REVIEW

\title{
The intubating laryngeal mask airway
}

A Steel

Emerg Med J 2005;22:47-49. doi: 10.1136/emj.2004.020644

$\mathrm{T}$ he laryngeal mask airway (LMA) is accepted as both a rescue ventilation and a primary airway management device in both the prehospital and emergency department environments. ${ }^{1-3}$ A modified version of the LMA, the intubating laryngeal mask airway (ILMA, LMA-Fastrach; Intavent Ltd, Reading, UK) exists, which, when combined with a modified tracheal tube, can be used for blind tracheal intubation. There is evidence that the ILMA is an effective means of maintaining ventilation and oxygenation in the prehospital, ${ }^{4}$ operating theatre, ${ }^{5}$ and emergency department ${ }^{67}$ environments. In addition, it has been reported to be effective in facial trauma, ${ }^{7}$ neck immobilisation, ${ }^{89}$ in a lateral position, ${ }^{10}$ while wearing a chemical protective hood, ${ }^{11}$ and while in a helicopter. ${ }^{12}$ Importantly, it has been shown to be effective even among inexperienced operators. ${ }^{6} 81314$ A best evidence equipment review was undertaken to assess whether, when compared with a conventional LMA, the ILMA would be of use as an airway rescue device.

\section{DESCRIPTION OF DEVICE}

The ILMA is a modified version of the LMA, which, in addition to permitting ventilation, is designed to facilitate blind tracheal intubation with a tracheal tube in an obtunded or anaesthetised patient. It has a soft inflatable laryngeal mask and a rigid, anatomically curved airway tube terminating in a standard $15 \mathrm{~mm}$ connector and is wide enough to accept a cuffed $8 \mathrm{~mm}$ tracheal tube. The rigid handle permits removal and "steering" of the device in relation to the larynx. The device measures about $20 \mathrm{~mm}$ in transverse diameter at its widest point. An epiglottic elevator bar in the mask aperture elevates the epiglottis when an endotracheal tube is passed through the aperture (fig 1)

\section{PURPOSE AND INDICATIONS}

The ILMA permits single handed insertion from any operator position, without moving the head or neck from a neutral position and without placing fingers in the patient's mouth. It can be used as an airway device in its own right, permitting ventilatory control and oxygenation between intubation attempts. Indications include use during difficult airway situations, specifically including the need for manual in-line stabilisation and situations where there is restricted access to the patient or when personnel with intubation skills are not available, or where there is suspected cervical spine injury. The laryngeal mask component serves to guide the reinforced tracheal tube directly to the glottis without displacing anatomical structures. Unless the patient is deeply unconscious or has had topical anaesthesia applied to their upper airway, this will require concomitant neuromuscular block. Intubation through the ILMA is contraindicated in the presence of oesophageal or pharyngeal abnormality, although oesophageal abnormality alone is not a contraindication to the use of the ILMA purely as a rescue ventilation device.

\section{CLINICAL SCENARIO}

A young adult is involved in a road traffic collision resulting in a head injury and lower limb entrapment. He has a reduced level of consciousness and is unable to maintain an effective airway. Tracheal intubation by direct laryngoscopy is impossible. You wonder whether the prehospital use of an ILMA as a primary airway management or rescue ventilation device would be better than a standard LMA.

\section{THREE PART QUESTION}

In [patients with a reduced level of consciousness] is [prehospital insertion of an ILMA] more or less likely to be [successful and associated with effective ventilation and oxygenation] compared with a standard LMA?

\section{SEARCH STRATEGY}

Primary sources of evidence (Medline and Embase) were searched using [intubating laryngeal mask airway, intubating LMA OR Fastrach.mp] with Medline and ["intubating laryngeal mask airway, intubating LMA OR Fastrach"] with Embase. This search strategy was checked with an information specialist. The same search strategy was applied to the Cochrane Library as a source of secondary evidence. In addition, a text word internet search and direct communication with the manufacturer was undertaken.

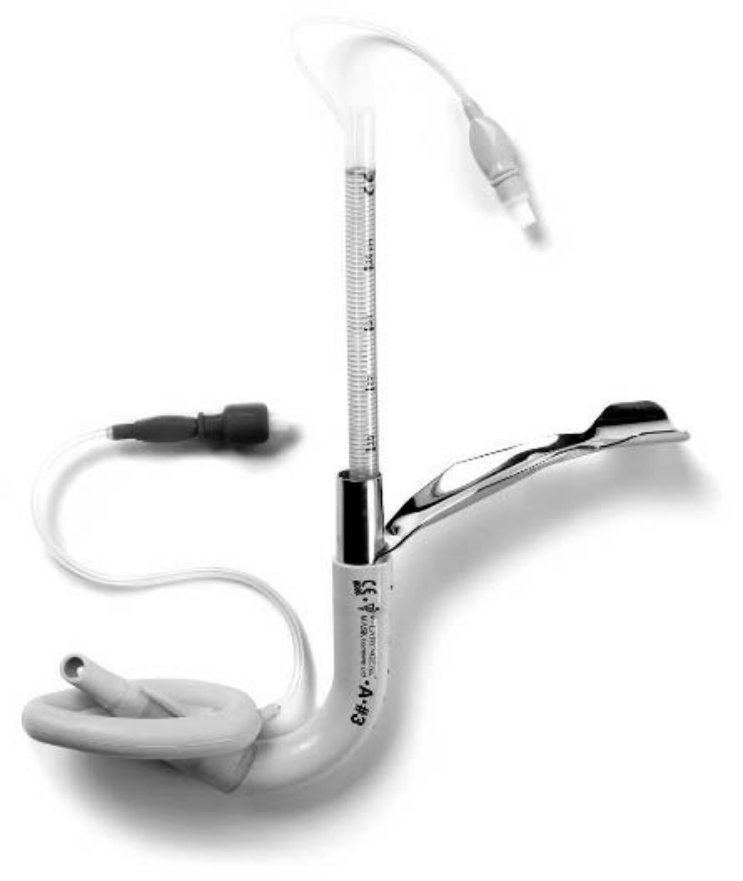

Figure 1 The intubating LMA with modified tracheal tube component inserted (with permission of The Laryngeal Mask Company Ltd). The tracheal tube component shown is minus its detachable $15 \mathrm{~mm}$ connector. 


\begin{tabular}{|c|c|c|c|c|}
\hline Reference & Study & Outcomes & Key results & Weaknesses \\
\hline 15 & $\begin{array}{l}\text { Randomised crossover study } \\
25 \text { electively anaesthetised } \\
\text { patients with manual in-line } \\
\text { stabilisation. LMA crossed over } \\
\text { with ILMA. Randomised first } \\
\text { device selection }\end{array}$ & $\begin{array}{l}\text { (1) Speed of placement } \\
\text { (2) Ease of placement } \\
\text { (3) Adequacy of ventilation } \\
\text { based on chest movement, } \\
\text { compliance and the } \\
\text { presence of leak }\end{array}$ & $\begin{array}{l}\text { (1) Insertion of ILMA was } \\
\text { significantly faster than } \\
\text { LMA ( } p<0.001 \text { ) } \\
\text { (2) Insertion of ILMA was } \\
\text { significantly easier than } \\
\text { LMA ( }<<0.001) \\
\text { (3) Adequate ventilation } \\
\text { achieved in } 100 \% \text { of ILMA } \\
\text { insertions } v 88 \% \text { of LMA }\end{array}$ & $\begin{array}{l}\text { (1) Unblinded } \\
\text { (2) Hospital based ASA 1-2 patients } \\
\text { (3) Patients with neck/upper } \\
\text { respiratory abnormality or at risk of } \\
\text { aspiration excluded } \\
\text { (4) Muscle relaxants used } \\
\text { (5) Capnography/pulse oximetry not } \\
\text { used }\end{array}$ \\
\hline 13 & $\begin{array}{l}\text { Randomised crossover study. } \\
55 \text { electively anaesthetised } \\
\text { patients. Randomised } \\
\text { to use either LMA or ILMA }\end{array}$ & $\begin{array}{l}\text { (1) Speed of insertion } \\
\text { (2) Successful ventilation } \\
\text { as shown by positive } \\
\text { end tidal } \mathrm{CO}_{2}\end{array}$ & $\begin{array}{l}\text { (1) No significant difference } \\
\text { in mean insertion time } \\
\text { (2) No significant difference } \\
\text { in success of ventilation }\end{array}$ & $\begin{array}{l}\text { (1) Unblinded } \\
\text { (2) Hospital based female patients } \\
\text { only } \\
\text { (3) Inexperienced operators } \\
\text { (4) BMI > 30/reduced mouth } \\
\text { opening/reduced neck movements } \\
\text { excluded }\end{array}$ \\
\hline 16 & $\begin{array}{l}\text { Prospective study. } 75 \text { electively } \\
\text { ancesthetised patients. } 24 \\
\text { inexperienced operators. LMA } \\
\text { crossed over with ILMA. } \\
\text { Randomised first device selection }\end{array}$ & $\begin{array}{l}\text { (1) Speed of insertion } \\
\text { (2) Adequacy of ventilation } \\
\text { based on chest expansion } \\
\text { and end tidal } \mathrm{CO}_{2}>4 \mathrm{kPa} \\
\text { (3) Pressure at which leak } \\
\text { developed around device }\end{array}$ & $\begin{array}{l}\text { (1) No significant difference } \\
\text { in insertion time } \\
\text { (2) No significant difference in } \\
\text { success of insertion or ventilation } \\
\text { (3) The ILMA was better at } \\
\text { providing adequate ventilation } \\
\text { without an audible leak } p=0.009\end{array}$ & $\begin{array}{l}\text { (1) Unblinded } \\
\text { (2) Hospital based ASA 1-2 patients } \\
\text { (3) Inexperienced operators } \\
\text { (4) Patients with risk factors for } \\
\text { regurgitation excluded }\end{array}$ \\
\hline
\end{tabular}

\section{SEARCH OUTCOME}

There were no randomised controlled trials comparing the use of the ILMA with that of a standard LMA in the prehospital setting. Three hospital based research reports were found to be relevant (see table 1). ${ }^{13} 1516$

\section{RESULTS}

These studies suggest that, in hospital, the intubating laryngeal mask is at least as quick and as easy to insert as a standard LMA. The ILMA is more likely to provide successful ventilation than a standard LMA. There were no significant complications reported as a result of using an ILMA.

\section{PRACTICAL CONSIDERATIONS Availability}

Most UK anaesthetic departments will have the device available as part of a difficult airway equipment set. Most emergency departments and ambulance services, however, will be unfamiliar with the ILMA and the prehospital care practitioner can expect the need to assist emergency department staff in its use. ${ }^{417}$

\section{Presentation}

The device comes packaged as three separate componentsthe ILMA, a straight reinforced tracheal tube and a stabiliser rod. The stabiliser rod is used to prevent dislodgement of the tracheal component while the LMA component is being extracted around it, although for short periods the LMA component may be left in situ to facilitate airway control on subsequent extubation. Three sizes are of ILMA are available-size 3 (children 30-50 kg), size 4 (adult 50-70 kg), and size 5 (adult $70-100 \mathrm{~kg}$ ). Use of a standard cuffed tracheal tube (rather than the specifically designed tracheal tube) is not recommended by the manufacturer.

\section{Sterilisation}

It is delivered non-sterile and must be cleaned and sterilised before initial use and before each subsequent use. Steam autoclaving is the recommended method of sterilisation. The ILMA device can be reused up to 40 times. The dedicated tracheal component can be steam sterilised and used up to 10 times. A single use plastic version of the ILMA is currently awaiting CE approval and has an anticipated launch date of early 2005. A single use dedicated tracheal tube will also be available in late 2004 .

\section{Training}

Complimentary video and manikin based training is provided by the UK distributor (http://www.intaventorthofix.com). This would normally be done within a half day session and include theoretical training, maintenance, and two consecutive successful manikin based insertions (which have been shown to predict successful insertion and ventilation among patients).$^{18}$

\section{Expiry}

The device is reusable and warranted against manufacturing defects for 40 uses or one year from the date of purchase (whichever is earlier).

\section{Cost}

Single reusable ILMA: £304. Single reusable tracheal component: $£ 46$. Complete set: $£ 1050$ (containing mask sizes 3, 4, and 5 with reinforced tracheal tubes size 7, 7.5, and 8 and three stabiliser rods). A reusable standard (non-intubating) LMA is $£ 91$ and the disposable standard (non-intubating) LMA (also available in sizes 3, 4, and 5) is $£ 9$ (IntaventOrthofix, personal communication).

\section{CLINICAL BOTTOM LINE}

There is reasonable evidence that the ILMA can be inserted with as much success as a standard LMA with the additional advantage of probable subsequent successful tracheal intubation if necessary. Individual practitioners may find the cost prohibitively expensive and the practical considerations of sterilisation overburdening. However, single use versions are expected to be significantly more affordable and should be available soon. For prehospital care practitioners or systems that regularly encounter difficult airways in patients anaesthetised or with reduced levels of consciousness, the ILMA is a useful rescue ventilation and primary airway management device that could be carried as an alternative to the standard LMA.

Funding: this work was supported by the MAGPAS Research Programme.

Conflicts of interest: none declared. 
Correspondence to: Dr A Steel, MAGPAS, 105 Needingworth Road, St Ives, Cambridgeshire PE27 5WF, UK; a-steel@doctors.net.uk

\section{REFERENCES}

1 Henderson JJ, Popat MT, Latto IP, et al. Difficult Airway Society guidelines for management of the unanticipated difficult intubation. Anaesthesia 2004;59:675-94. (http://www.das.uk.com/guidelines/ guidelineshome.html).

2 Pollack CV. The laryngeal mask airway: a comprehensive review for the emergency physician. J Emerg Med 2001;20:53-66.

3 Gibbs M, Swanson E, Tayal V, et al. Use of the intubating laryngeal mask airway in prehospital patients with failed rapid sequence intubation. Acad Emerg Med 2003; 10:467.

4 Mason AM. Use of the intubating laryngeal mask in pre-hospital care: a case report. Resuscitation 2001;51:91-5.

5 Ferson DZ, Rosenblatt WH, Johansen MJ, et al. Use of the intubating LMAFastrach in 254 patients with difficult-to-manage airways. Anaesthesiology 2001;95:1175-81.

6 Martel M, Reardon RF, Cochrane J. Initial experience of emergency physicians using the intubating laryngeal mask airway: a case series. Acad Emerg Med $2001 ; 8: 815-22$

7 Agro F, Brimacombe J, Brain Al, et al. The intubating laryngeal mask for maxillo-facial trauma. Eur J Anaesthesiol 1999;16:263-4.

8 Reeves MD, Skinner MW, Ginifer CJ. Evaluation of the intubating laryngeal mask airway used by occasional intubators in simulated trauma. Anaesth Intensive Care 2004;32:73-7.
9 Wakeling HG Bagwell A. The intubating laryngeal mask (ILMA) in an emergency failed intubation. Anaesthesia 1999;54:305-6.

10 Komatsu R, Nagata O, Sessler DI, et al. The intubating laryngeal mask airway facilitates tracheal intubation in the lateral position. Anesth Analg 2004;98:858-61.

11 Talbot TS, Cuenca PJ, Wedmore IS. Intubating laryngeal mask airway versus laryngoscopy and endotracheal intubation in the nuclear, biological and chemical environment. Mil Med 2003;168:876-9.

12 Swanson ER, Fosnocht DE, Matthews K, et al. Comparison of the intubating laryngeal mask airway versus laryngoscopy in the Bell 206-L3 EMS helicopter. Air Med J 2004;23:36-9.

13 Burgoyne L, Cyna A. Laryngeal mask vs intubating laryngeal mask : insertion and ventilation by inexperienced resuscitators. Anaesth Intensive Care 2001;29:604-8.

14 Levitan RM, Ochroch EA, Stuart S, et al. Use of the intubating laryngeal mask airway by medical and nonmedical personnel. Am J Emerg Med 2000;18:12-16.

15 Asai T, Wagle AU, Stacey M. Placement of the intubating laryngeal mask is easier than the laryngeal mask during manual in-line neck stabilization. Br J Anaesth 1999;82:712-15.

16 Choyce A, Avidan MS, Shariff A, et al. A comparison of the intubating and standard laryngeal mask airway management by inexperienced personnel. Anaesthesia 2001;56:350-69.

17 Mackenzie R. The ILMA in pre-hospital care. Resuscitation 2002;53:227-8.

18 Choyce A, Avidan MS, Patel C, et al. Comparison of laryngeal mask and intubating laryngeal mask insertion by the naiive intubator. $\mathrm{Br} J$ Anaesth 2000;84:103-5. 